\title{
Social stories to enhance communicative strategies among autism spectrum disorder (ASD) children
}

\begin{abstract}
The use of strategies by children with developmental disabilities in repairing their communicative breakdowns has received little attention in the research literature to date. These children may also have fewer strategies available to them. By using Tarone's Taxonomy (1980) of communicative strategies, this current study was trying to further unravel and discuss how children with autism spectrum disorder (ASD) could enhance their spoken communicative intent in conversing about moral values. Audiotaped, semi-structured conversational data was collected from four children (two low functioning autism and two Asperger Syndrome) with autism ASD. They were seven to nine years old from Sekolah Kebangsaan Desaminium, Seri Kembangan, Selangor. Two social stories were told to the subjects; Visiting atuk and nenek in Kampung and Being Kind to Animals with two moral values underpinned in each social story. Findings revealed that all four ASD children were using almost all the nine communicative strategies except for word coinage. The study concluded that Tarone's Taxonomy (1980) of communicative strategies was really helpful in unravelling the communicative intent of a group of ASD children in talking about moral values based on the social stories told to them. Having said so, future research still needs to consider how these strategies or perhaps other communicative strategies could be used as attempts to repair communicative breakdowns among ASD children. It is hoped that the impairment in understanding others' mind hinders the development of an intent-based moral judgment in ASD children.
\end{abstract}

Keyword: Tarone's taxonomy; Communicative strategies; Social stories; Moral values; Autism 